\title{
A Study on the Planning and Design for the Image of Jimei School Village Entrance
}

\author{
Qiduan Chen ${ }^{1,}$, Jielin Wang ${ }^{2, b^{*}}$ \\ ${ }^{1}$ Jimei University School of Fine Arts and Design, Jimei District, Xiamen, Fujian, China \\ ${ }^{2}$ Jimei University School of Fine Arts and Design, Jimei District, Xiamen, Fujian, China \\ a1140751800@qq.com \\ $b^{*}$ wangjielin77@163.com
}

\begin{abstract}
This paper aims to explore the correlation between the planning and design of entrance image of Jimei School Village (Ji Mei Xue Cun) and landscape planning for urban development. Access to the concept of sustainable development, Jimei School Village sites new challenges: the spatial order has long been excluded and the spatial utilization rate is low; The modern landscape cannot fit in with ancient stone archway; and traffic at the century-old entrance is chaotic, which threatens students' safety. Nowadays, there is a height difference at the entrance of Jimei School Village. Many roads converge to form an acute angle space, and people and vehicles are mixed. The entrance of Jimei School Village is surrounded by tall trees and shrubs, which have obvious boundaries with the city. It is difficult for them to merge with each other and develop together. Through literature analysis and field research, we will use the planning of Jimei School Village to demonstrate the spatial pattern of entrance nodes, propose planning concepts and design principles, corridors and the hierarchy of entrance image, analyze space from "point, line and plane", and put forward the planning principle and design of the entrance image by combining the Jimei School Village with the surrounding urban landscape. It is hoped that the development of Jimei School Village can be combined with the urban development to form sustainable development of the economy, society, and environment, enhance people's sense of belonging and comfort while still inheriting the culture of Jimei School Village, making people have a common memory of establishing emotional connection in Jimei School Village and form a city image.
\end{abstract}

Keywords : spatial development, campus entrance, urban planning, sustainable development

\section{PREFACE}

The overseas Chinese culture and Kageng spirit are the cultural characteristics of Jimei School Village in Xiamen City, Fujian Province, but Jimei Village lacks orientation in the tourism industry. Compared with Gulangyu, Zhongshan Road pedestrian street, Zengzuo'an and other tourist attractions, the development of Jimei School Village is hindered by unreasonable spatial planning, destruction of ecological environment, disconnection between the development of Xuecun and urban development. However, the ancient archway at the entrance of Jimei School Village is not clear in the function of the entrance space and the quantity of tourists is not high because there are traffic disorder problems and no space for tourists and dense plants around it.

Xiamen's development plan is based on the development orientation of "Happiness Siming,
Innovation Huli, Vitality Haicang, Humanities Jimei, Rich Tongan, Model Xiangan ". On the premise of sustainable development, it combines the development of Jimei School Village with the urban planning and development of Xiamen city, promotes the quality of space, carries forward the culture and spirit of Jimei School Village, and creates an important natural and cultural tourism center in the country and a humanistic city with multiple blending. ${ }^{[3]}$

\section{ANALYSIS ON THE PRESENT SITUATION OF SPATIAL FORM IN JIMEI SCHOOL VILLAGE}

Jimei School Village is located at the north bank of Xiamen Island, backed by Tianma Mountain, surrounded by the sea on three sides. In the early 1920s, Chen Jiageng collected aesthetics village permanent peace school village. Since the founding of the People's Republic of 
China from 1937 to 1949, the development of Jimei School Village was blocked and the architecture and environment were seriously damaged. ${ }^{[1]}$

Jimei School Village is an important historical track and representative building in the modern and modern times of the Republic of China. Through the precipitation of a hundred years, it has a strong historical and cultural background and is the main place to display the cultural and artistic exchanges between Jiageng. Jimei School Village is a spontaneous university town, and the spatial layout is "learning in the village, the village in the city ". The spatial form formed by the integration of colleges and towns promotes the integration of campus culture and community culture. Since the formation of Jimei School Village has a history of more than 100 years, it is only self-developed, which needs to be combined with the renewal and development of the city to strengthen the organic interaction between the university city and the city. ${ }^{[2]}$

\subsection{Analysis of the status of access space}

The entrance of Jimei School Village forms a sharp intersection with slope road, which is located at the intersection of Yinjiang Road, Cenxi Road, Jiageng Road and Aoyuan Road. The traffic confusion, the difficulty of dealing with the sharp angle and the unclear spatial function are all caused by the slope. The main reason for the sharp angle space is the road demand of Xiamen Bridge. The application of acute angle element in planning and design needs careful consideration. The sharp angle space has the characteristic of spatial tension and strong centripetal force, but it is difficult to be used because of the sharp scale being felt negative or dead angle. ${ }^{[6]}$ At the intersection of the carriageway, it is necessary to ensure that the driver's vision is wide, so it is necessary to avoid the sharp angle space. If it is difficult to avoid, it is necessary to use the diversion island to alleviate the problem caused by the sharp angle intersection. ${ }^{[7]}$

Because of the slope, the entrance of Jimei School Village forms a sharp intersection of many main roads. There is no diversion island, only marked with landmarks, but there are many pedestrians and tourists, and no pedestrian passage is marked at the entrance, so it is difficult to ensure safety. However, when the diagonal intersection produces a non- 90 degree angle, it breaks the regular composition, brings a sense of tilt rupture, and emotional expression can add vitality to the neat rectangular frame. The intersection of the diagonal road at the entrance of Jimei School Village is a valuable information left by the urban development network, a link between the city and Jimei School Village, and an entrance for people to understand Jimei School Village. ${ }^{[4]}$

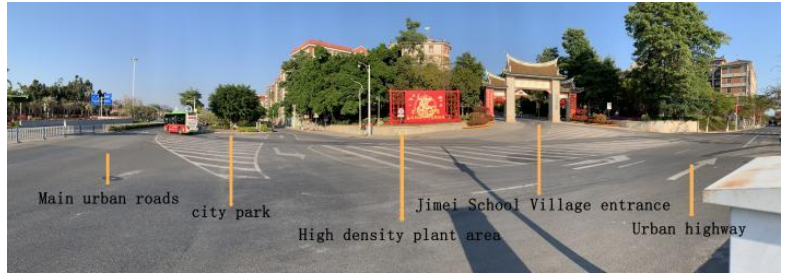

Figure 1 Jimei School Village entrance and surrounding status (photo source: author's own photo)

\subsection{Analysis of the surrounding environment}

Jimei ancestor tomb is just on the right side of the entrance to Jimei School Village, commonly known as "Port Tomb ", built in Yuan Dynasty and rebuilt in Ming Dynasty. On the left is the Haitong Building of Jimei University School of Navigation, which has the characteristics of Jiageng architecture. As soon as people enter the entrance and see Haitong Building, they can know that they have come to the study resort. At the junction of the entrance and the city road Ceng East Road there is a Cengxi Community Park that is less well known. The park is long, facing the school village side planted large trees and shrubs, the park and Jimei School Village separated, which means there will be a "high wall "between Jimei School Village and the city. Just opposite to the entrance is the small sea area under the Xiamen Bridge, and the scenery of Jimei School Village can also be seen on the Xiamen Bridge.

\section{RELEVANCE OF URBAN LANDSCAPE DESIGN AND JIMEI SCHOOL VILLAGE}

Jimei School Village is a special part of Xiamen and a scenic spot for people. The cultural background represents the city image of Xiamen. By making the collection of aesthetic village a means of urban marketing, the development of urban tourism in Xiamen can be enhanced. Glasgow in the UK is an extreme case of the decline of industrial cities. Depressions and rising unemployment have led to a decline in population because poor city image prevents investors from investing. Through a series of urban marketing means, we will strengthen the central region and improve the urban infrastructure, and the image focuses on art and culture, and rebuild the city image to promote the economic recovery of Glasgow city. Therefore, as a tourist attraction in Xiamen, the landscape design in the city also needs to be integrated into the "shadow" of Jimei School Village, become the symbol of Jimei district in Xiamen, establish excellent city image, and promote economic development. ${ }^{[15]}$ 


\subsection{Planning concept}

The first and most important point is to integrate the city with the Jimei School Village. The logic of urban construction is no longer expansion but nostalgia, and then protect history, so that people's collective memory is no longer slowly weakened. Collective memory allows us to have a close relationship with the urban landscape, let us have feelings for the city. Jimei School Village has experienced more than 100 years of baptism, witnessed the changes of Xiamen, is an important historical memory in this city, but also the memory point of Xiamen, so that Jimei School Village and the surrounding urban texture and natural system can be perfectly combined, reflecting the city and complementary with each other.

Sustainable development is also essential. China's land and space is a multilateral and complex system, the main theme of the planning is the harmonious development of man and nature, the long-term goal is the sustainable development of the environment and the effective utilization of resources, the earth's resources are limited, and the human needs are unlimited. The development goal of natural system is to be sustainable and form the common development of man and nature. Land abandonment can have a serious impact on the environment and human health. Because of the unbalanced distribution of environmental risks and pollution, it is proposed that everyone is equal, and everyone has the right to know and speak about the environment in public. Through the landscape design and road system planning of Jimei School Village, it has become a model of the renewal process in the urban environment. ${ }^{[14]}$

In the planning concept, we also need to provide people with important historical heritage and cultural value. Jimei School Village is a "joint work of nature and mankind ", where heritage and cultural resources are located, so that people can better understand history and local culture, carry forward the historical and cultural characteristics of Jimei School Village and reshape the vitality of space. The city culture characteristic is formed through the long city construction and has been continuing, and it will become the city's business card. When it come to the collection esthetics village, we will think of the dragon boat culture, the Jiageng building. Like the Weiyang Square of Mancheng Mausoleum Mountain Han Culture Scenic spot, the scenic spot analyzes the characteristics of the entrance landscape design, integrates the entrance design with the development of the scenic spot, and creates the local cultural theme landscape.

\subsection{Designing principles}

Designing should always maintain the principle of people-oriented. Man is the main body in space, extensive participation, communication and interaction in space. In the design of Jimei School Village, it is necessary to understand their needs with the surrounding residents and students. For example, after we walk 500 to 800 meters on the road, a square rest should be set up so that people can pause for communication and interaction, making people travel and sightseeing full of rhythm.

The principle of adapting measures to local conditions is also very important in design. According to the natural background, urban skeleton and urban texture of Jimei School Village, it is necessary to plan and design according to the local conditions, so as to improve the quality of the entrance space. In the urban design of Benxi County, the elements of "water" in Benxi County are extracted as urban images to carry out planning and design, and the concept of water in Benxi County is transformed into three parts:" holding water "," floating leaves "and" golden corridor ". In other words, it is necessary to understand the location, hydrology, topography and geomorphology of Jimei School Village according to the present situation, and extract the image elements of Jimei School Village, such as Jiageng Architecture, Dragon Boat, Sea and so on, and put the concept into the planning and design. ${ }^{[12]}$

\section{PLANNING AND OPERATION OF IMAGE AT THE ENTRANCE OF AESTHETICS VILLAGE}

In planning and design of Kevin Lynch, it is divided into five elements: path, edge, region, node and landmark. The first element is path, which is the main impression of people's image of the city, and the node is the gathering point of the city, which is an important feature to understand the city. Urban image is divided into material image (five elements) and cultural image. In the planning and design of Jimei School Village entrance, the road elements and node elements in urban image are mainly analyzed. ${ }^{[5]}$

Jimei School Village is a landmark in Jimei District of Xiamen City, while the entrance archway is an important node of Jimei School Village. One of the biggest problems the city is faced with is traffic, so the urban road occupies a large part of the urban land, so the complete plot is divided and blocked, so the resulting small plot can not be used effectively. The sharp intersection with slope will form more complex traffic conditions. The main reason for the formation of sharp angle space is the road demand of Xiamen Bridge. The sharp angle space formed by the road can be planned as a public open space. It is a good solution to use architecture to resolve the sharp angle space of the sharp angle intersection, but the entrance of Jimei School Village can not do so because it is the intersection of the main road and has a large slope. ${ }^{[10]}$ In the planning and design, it is mainly necessary to solve the problem of road classification and spatial function, to determine the 
attributes and values of the entrance space, to improve the utilization rate of the space, and make the space environment sustainable development.

\subsection{Exploration of Space Pattern of Entrance Node and Corridor}

Because of the intersection of many main roads and auxiliary roads in the entrance of Jimei School Village, urban traffic has an impact on the campus entrance, and the location of the bus station will also change the space of the campus entrance. It is a method to choose the underpass in the reconstruction and renewal of the main entrance road of Wuhan University. There are many "archways" in colleges and universities in our country, such as Nanjing University, Fudan University, Tongji University and so on. Most of them use motor vehicles to enter from the middle and pedestrians from both sides. In the reconstruction of the entrance space of Tongji University, the original school gate is retained, the porch with transitional function is designed around the school gate, the elliptical square is formed, and the people and cars are mixed into and out of the original school gate in the middle of the square. Motor vehicles detour from both sides. ${ }^{[16]}$

In the space mode of entrance node and corridor, we should consider the problems of road intersection, bus station location and so on, the order and law formed by planning and design make the space full of its own rhythm and rhythm, with rich appeal and strong expressiveness.

\subsection{1. dot space (entry node)}

The intersection of the road will mainly form twoway intersection " $\mathrm{T}$ " intersection or " $\mathrm{X}$ " intersection, three-way intersection " $\mathrm{Y}$ " intersection, and multi-way intersection. There is a height difference between the entrance and the urban road, and many urban roads converge to form multi-road intersections. According to the present situation of Jimei School Village, the entrance intersection of Jimei School Village is transformed into a thin body. Combining the terrain with the road space, the angle radius and the present situation are reduced, and the pedestrian crossing distance is shortened to set up the safety island. In this way, the entrance node of Jimei School Village will become the place where people can gather in sight, safely appreciate the beautiful scenery of the entrance node of Jimei School Village while playing or taking classes, and taste the humanistic feelings of Jimei.

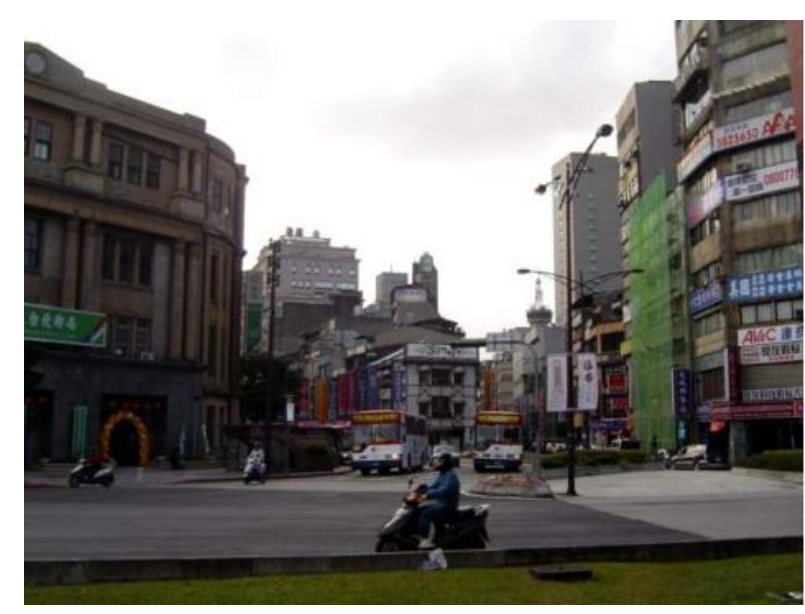

Figure 2 Intention Chart (photo source: author's own photo)

\subsection{2. linear space}

Linear space mainly refers to roads. At the entrance of Jimei School Village, there is no clear division of motor vehicle pavement, non-motorized carriageway and sidewalk, and there is a sharp space between the road and the road, which leads to traffic confusion and pedestrians will be in danger. In road planning, it is necessary to have grade, continuity, rhythm, hierarchy and characteristics to divide the driveway, bus priority lane, non-motorized lane and so on to ensure the safety of pedestrians. Because there is only one entrance carriageway at the entrance of Jimei School Village, there is high density greening on both sides, in which the sidewalk can be planned, so that tourists and pedestrians can enter the school village safely, and the sightseeing rate of Jimei's ancestral tomb at the entrance can also be improved. ${ }^{[19]}$

\subsection{3. faceted space}

A pause space is set up opposite to the entrance of Jimei School Village for people to take pictures and provide people with rest opportunities. Because the entrance of Jimei School Village is opposite to the sea, it is necessary to make use of it to renew the planning and design, so that the city can be combined with the Jimei School Village, and the tourists have not yet entered the Jimei School Village to feel the cultural atmosphere. Like the examples of Nanjing Confucius Temple, Beijing Wudaokou Commercial Square ,911 Memorial Park in the United States and so on, each public space conveys the local cultural and historical value, hoping that the public space can meet the needs of people, provide rich performance for public life, and make people get emotional sublimation in the artistic communication of public space. ${ }^{[18]}$

Public space is essentially a human need, and the public needs to participate. Combining the diversity of daily life with the public space, people need regular cultural events as a means of shaping the culture of public 
space. In Milan, both festivals and peacetime can be carried out in the streets of social activities. If there is space for people to communicate at the entrance of Jimei School Village, for example, students, tourists and residents can participate in school celebration, we can better spread Jimei culture.

\subsection{Perpetual Thinking on Image Design of Entrance}

In everyday life, the environment in which people live is not only visual, but also the meaning of sound, smell, texture and human heart. In such a state, the memory of a place is not just a certain symbol or element, but an impression of the interaction of many related things around it. Especially in cities, the impression of Jimei School Village will be more complicated ;" usually our cognition of the city is not constant, but mixed with some other related affairs, part of the cognition; almost all the senses operate at the same time, and the so-called image is the whole mixture."(Lynch ,1960, p.2) ${ }^{[8]}$

In the 1980s, China began to introduce urban design, which made great contributions to the urban construction of our country, made the diversified development of urban design, shaped the image of the city, and put the image of the city into people's minds. Kevin Lynch focuses on studying understanding the nature of the city from the citizens, making the city "readable" and forming "communicationable city ". In an era of such rapid development, we should not only understand the significance of analyzing the urban network thousands of years ago, but also take into account the development context of the future cities. ${ }^{[5]}$

The global city tends to be unified, the city content has less novel characteristics, the humanities culture has faded, people will stay in the urban space less and less. From the perspective of futurology, the historical and cultural value of Jimei School Village is difficult to replace, and has been delimited as the "purple line" protection range. ${ }^{[17]}$ The renewal of the city needs to deal with the "sublation" of culture, and also to find how to embody the design method of regional spirit. Urban context is intended to urban culture and urban memory, with landscape to be the form of expression. Understanding a city is the cognitive process of multiple perspectives, and the context of the city is reflected in the renewal and change of the city. The context of the city has been continuing, the characteristics of urban culture is formed through a long period of urban construction, will become the business card of the city. When it comes to Xiamen, we will think of Minnan culture, Jiageng architecture. Jiageng architecture is unique in the history of architecture, cultural connotation and historical value are incalculable, is the context of urban image. With the theme of Jiageng culture, we improve the quality of space. $^{[11]}$
Jimei School Village needs to be inherited and developed in protection, and planed and designed in protection. The entrance ancient stone archway is a nonrenewable resource, so that the ancient stone archway can develop sustainably. It is necessary to perfect the protection policy, not to cause irreparable losses, and to make the village "live" and radiate vitality. ${ }^{[12]}$ It is the goal of the future development of scenic spots to make tourists feel their cultural connotation and historical background, landscape and culture. ${ }^{[17]}$

\section{CONCLUSION}

At present, in domestic colleges and universities, the axis layout is generally adopted, emphasizing symmetry, but not from the reality. In the Bauhaus school planning and design, the entrance is divided into separate spaces to get rid of the symmetry axis. The development of colleges and universities is more and more convergent, without its own characteristics, some university images and urban planning cannot be well integrated, difficult to land implementation. ${ }^{[16]}$ Therefore, it is necessary to integrate urban development with the development of Jimei School Village, retain the original archway at the entrance of Jimei School Village through the planning and design of the entrance image, replan the pedestrian access route, and divert people and cars, improve the quality of Jimei School Village entrance space, keep people's collective memory and sense of belonging.

The form and quality of urban space can determine people's perception of the city and it is people's active behavior. Kevin Lynch's ideological theory accords with the trend of urban development in China and needs to concentrate on developing the uniqueness of a single city. Urban planning and design is a top-down activity, everyone needs to participate in order to maintain the sustainability of the city. ${ }^{[9]}$ Urban image refers to the residents' perception and understanding of the surrounding environment, the urban impression formed by human imagination, so that people who have memories will form emotions. Emotions towards a place occur when people are separated from their identity and self-consciousness and attached there through a sense of cultural belonging. Two important aspects in space are collective memory and sense of belonging, which can make residents establish emotional connection to space. Based on the communication and interaction of residents, it becomes the construction of local sense. Local sense is an emotion that people interact with a region for a long time to form a common idea, individual and collective, forming collective memory. The comfortable space is helpful to people's social communication, to meet the needs of people's stay, to share local culture, and to make the city and the aesthetic village develop sustainably. ${ }^{[13]}$ 


\section{REFERENCES}

[1] Chen Fan, Huang Tangfen. Spatial Characteristic Analysis of "Learning City" Historic and Cultural District — Taking Shigu Road, Ji Aesthetics Village, Xiamen as an example [J]. Chinese and foreign buildings 2019(04):97-100.

[2] Gao Yanying.[D]. on Space Development of Jimei School Village and Its Enlightenment to the Construction of University City Overseas Chinese University ,2014.

[3] Li Yangdong, Tang Lu. Study on the Construction Strategy of Slow Community in Historical Block under the Concept of "slow City "__ Taking Jimei School Village in Xiamen as an example [J]. Chinese and foreign buildings 2017(06):96-100.

[4] Wang Yuchen. A Study on Contemporary "Broken Line" Landscape Space [D]. Southeast University ,2016.

[5] Wang You. A Study on Kevin Lynch's Thought of Urban Communication [D].10 Hebei University ,2018.

[6] Hu Jing. Design [J]. of Small Scale Sharp Space Chinese and foreign buildings 2015(09):102-104.

[7] Li Yi, Shui Tianhui, Pan Juan. The Art of Acute Angle - The Application of Acute Angle in Landscape Design [J].1 Chongqing Architecture 14(06):22-25.

[8] Norul Fazlina Khashim,Mazran Ismail,Ahmad Sanusi Hassan and Najib Taher Al-Ashwal.A Study on Kevin Lynch's Urban Design Elements: Precinct 9East Putrajaya[J]. International Transaction Journal of Engineering,Management,\&Applied Sciences \&Technologies,2017,8: 153-167.

[9] Yan Tang,Sisi Liang,Ruizhi Yu.Theoretical and Practical Influences of Kevin Lynch in China[J]. Journal of the American Planning Association,2018,84(3-4).

[10] Chen Gaotao. A Study on the Architectural Design of Chongqing Road Intersection under the Limit of Triple Condition [D]. Chongqing University ,2017.

[11] Yan Zijie, Ma Mingju, you Xiufeng. Present Situation and Countermeasures of the Protection of Famous Villages and Famous Streets in Historic Towns_- Taking Xiamen City as an Example [J]. Development Studies ,2016(03):72-78.

[12] Lin Pengfei, Yuan Jingcheng, Chen Shi. A probe into the shaping of urban design features under the guidance of A]. Image Theory China Urban Planning Society, Hangzhou Municipal People's Government. Sharing and Quality_Proceedings of the 2018 China Urban Planning Annual
Conference (07 Urban Design)[ C]. China Urban Planning Society, Hangzhou Municipal People's Government: China Urban Planning Society ,2018:10.

[13] Kong Xiang, Ling Lin, Chen Dan. The role of public space in the local remolding of residents of new communities around the development zoneTaking typical communities around Changsha Economic and technological Development Zone as an example [J].1 Urban issues ,2015(09):49-56.

[14] Li Wei, Yang Chengxing, Wang Lucang, Feng Bin, Quan Jinzong. Charm Land and Space: Land and Space Planning Strategy [J]. of Reshaping Regional Characteristics Journal of Natural Resources ,2020,35(03):501-512.

[15] Ronan Paddison.City Marketing,Image Reconstruction and Urban Regeneration[J]. Urban Studies, 1993,30(2).

[16] Hu Hao. [D]. on the Reform and Renewal Strategy of Campus Entrance Space in Domestic Universities South China University of Technology.

[17] Yang Xiaozhou. City context protection and regeneration strategy from the perspective of [D]. art design Tianjin University ,2016.

[18] Gao yueying. analysis of the embodiment of urban culture in the arrangement of garden plants [J]. modern horticulture, 2020,43(20):110-111.

[19] Ouyang dong, Zhao sidong, Sha Ou, Li Lin. environment, artistic conception and mood-planning method of scenic spots based on urban image theory [J]. planner, 2016,32(04):91-96. 